\title{
LA RAZÓN Y LA ESENCIA
}

\author{
Reason and Essence \\ Razão e Essência
}

Enzo Arial Villarroel

Universidad de Valparaíso, Chile. Fono: +56 997493794 . Correo electrónico: enzosaberestar@gmail.com

\section{Resumen}

Vivimos tan absortos en la racionalidad que ni siquiera nos preguntamos si existe otra manera de abordar la experiencia educativa y aun cuando existen dilemas y conflictos que nos aquejan, seguimos intentando encontrar la solución con los mismos elementos que nos generan el malestar. Claramente hemos sucumbido en una práctica que además de generar malestar también se ha vuelto peligrosa porque no parece favorecer el desarrollo pleno del ser humano. ¿Será posible, a pesar del dominio de la razón echar un vistazo en otra dirección? ¿A otra posibilidad del hacer que nos muestre otro camino de entendimiento?

Palabras Clave: esencia; razón; fenomenología; cuidado; educación; entendimiento; aparecer.

\begin{abstract}
We live so absorbed in the rationality that we do not even ask ourselves if there exists another way of approaching the educational experience and even if there exist dilemmas and conflicts that afflict us, continue trying to find the solution with the same elements that us generate the discomfort. Clearly we have succumbed in a practice that beside generating discomfort also has become dangerous because it does not seem to favor the full development of the human being. Will it be possible, in spite of the domain of the reason to throw a glimpse in another direction? To another possibility of to do that it shows us another way of understanding?
\end{abstract}

Key words: essence; reason; phenomenology; care; education; understanding; appear. 


\section{Resumo}

Nós vivemos tão absorvido na racionalidade que nós nem mesmo maravilha se outro modo existe de chegar a experiência educacional e até mesmo quando dilemas e conflitos que nós sofremos, exista nós continuamos tentando achar a solução com os mesmos elementos que nos geram a intranqüilidade. Claramente nós sucumbimos em uma prática que também se tornou além de intranqüilidade geradora perigoso porque não parece favorecer o desenvolvimento cheio do ser humano. Será possível, apesar do domínio da razão para dar uma olhada em outro endereço? Para outra possibilidade de fazer que mostra para nós outro a caminho de entender?

Palabras chave: Essência, para razão, para fenomenologia, cuidado, educação, compreensão, se aparecer. 
Este artículo tiene como propósito compartir una reflexión preliminar acerca de nuestra situación educativa actual. Por situación me refiero a como "habitamos y construimos" nuestra experiencia educativa, pues al parecer persiste la sensación de que la educación con sus prácticas y creencias no es una morada acogedora.

Pero ¿en qué consiste la esencia del habitar?

Habitar (...) quiere decir: permanecer a buen recaudo (...) replegado en lo libre que cuida cada cosa llevándola a su esencia. El rasgo fundamental del habitar es este cuidar. (Heidegger, 1994: 4)

Acogiendo las palabras de Martín Heidegger no es trivial preguntarnos si nuestra educación constituye un auténtico habitar. Si habitar significa cuidar algo en su esencia, nos da la impresión que este no es el escenario en el que se asienta nuestro quehacer. El centro de nuestra educación no es la esencia, pero si lo es el saber racional y la atención que le prestamos al desarrollo del conocimiento intelectual. Hemos convertido nuestras instituciones en verdaderos estancos de conocimiento; especializado y refinado, pero incapaz de responder a ese cuidado esencial, que consiste en dejar que algo aparezca en su esencia, difícil tarea si lo que domina en nuestra práctica educativa, es la instrucción y no el aparecer.

Con el fin de facilitar la lectura y no incurrir en equívocos respecto al término "esencia", propongo entenderlo, como aquello que tiene la fuerza para mostrarse por sí mismo sin la intencionalidad interpretativa de la razón.

"Lo que se muestra de esa manera se muestra con fuerza y al mismo tiempo como una demanda. Desde el trasfondo oculto de los fenómenos, de pronto, algo sale a la luz como un rayo y nos muestra qué hay que hacer”. (Hellinger, 2005: 42)

Nuestra educación actual, se consagra más bien a enseñar formas de conducirnos en el mundo, en lugar, de quedar abiertos a lo esencial. Bajo tales condiciones, nuestra educación se vuelve rutinaria y toda forma de creatividad, no es más que un ligero intento de hacer digerible algo que está destinado a indigestar. 
Si Habitar significa cuidar y llevar algo a su esencia, entonces estamos muy lejos de convenir que nuestra educación sea un auténtico habitar.

Aun cuando el discurso educacional actual este sujeto a políticas de innovación, los estudiantes continúan "esperando" que el educar indique lo que hay que hacer y los educadores "esperando" que los estudiantes sigan las instrucciones. Es muy difícil promover una autentica innovación, pues constituye una disposición a "dejar aparecer" y los educadores, por lo general, siempre dejamos una puerta de escape, de modo tal, que si todo falla podemos volver al escenario acostumbrado, donde reina el hastío y la rutina, no obstante, todos sabemos allí qué hacer y qué esperar.

Dejar que algo aparezca en su esencia es un acto de apertura a lo desconocido, diametralmente distinto, a la premisa de que todo se encuentra al alcance de una explicación o descripción del mundo, tal como nos sugiere la racionalidad reinante. No obstante, hay parámetros de ese mundo desconocido al cual la razón simplemente no puede acceder porque tiene sus limitaciones. Limitaciones que se condicen con sus criterios de validez y su tendencia a cerrar el círculo del entendimiento, como si fuese posible llegar a una convicción final y conclusiva.

“Algo se vuelve convicción cuando pasa más allá de sus límites y se le otorga validez generalizada como si pudiese ser válido para todo en general. Como si el entendimiento realmente hubiera llegado a un fin". (Hellinger, 2008: 42)

Por eso, reconocer el límite de la racionalidad es fundamental como punto de partida de una forma distinta de tratar con la experiencia educativa, pues desde el punto de vista de la esencia, no se puede llegar a un entendimiento final, porque todo se encuentra en apertura y dotado de un movimiento creativo incesante.

Solo hay rutina allí donde la razón aprende repitiendo. En cambio, lo esencial es inaprensible y en ella es imposible identificar regularidades, es siempre sorpresiva y emergente. Como educadores tenemos que aprender a navegar en ese escenario donde reina la esencia y aprender a refrenar a la razón respecto a esa urgencia de descubrir patrones y regularidades. La razón no sabe esperar la "aparición de lo esencial", más aún piensa que si 
no premedita, intenciona y planifica nada va a acontecer. Por eso, nuestro quehacer como educadores, se encuentra cautivo de un exceso de planificación, que si bien, es funcional, no puede continuar dirigiendo la totalidad de nuestros actos.

Esta dominante demanda de planificación se entiende a partir de una determinación esencial de la razón como una señalada facultad de principios y categorías. Por eso, lo que aquí se propone es suspender esta inclinación a premeditar la experiencia, para dar lugar, a aquello que puede aparecer sin tener que ajustarse a ninguna categoría.

\section{(...) la esencia de la razón se funda en el hecho de que, para toda aprehensión de}

lo ente en su ser, el ser mismo se halla ya siempre aclarado como aquello que acontece en su verdad. (Heidegger, 2000: 4)

En efecto, La razón tiene el poder de hacernos entrar en la ilusión de que aquello con lo cual tratamos como experiencia ya se encuentra de antemano aclarada, por tanto, entramos en ella, sin respeto, sin atención, sin alerta, como si fuese un lugar común y conocido, tal vez por eso, nuestros estudiantes viven su experiencia educativa como una agonía y los educadores la viven como un desagravio a su esfuerzo y dedicación. Sin darse cuenta que es precisamente ese exceso de claridad la que los priva de una experiencia esencial e inolvidable. Si deseamos tener una experiencia inolvidable en el ámbito educativo, no podemos entrar a una sala de clases acompañados con ese exceso de claridad, tenemos que aprender a entrar allí- tanto educadores como estudiantes- con incertidumbre, con nuestra atención alerta. En esas circunstancias no hay tiempo para la distracción ni el aburrimiento, pues todo deja de ser inofensivo y se vuelve peligroso.

"El secreto para cultivar la existencia más fecunda y más gozosa consiste en vivir peligrosamente" (Nietzsche, 2002:283)

Lo cual no significa correr riesgos innecesarios. Vivir peligrosamente significa, antes bien, entrar en la experiencia educativa, reconociendo en ella una voluntad de poder, reinterpretadora y dadora de forma. Hablamos de vivenciar la experiencia educativa como una potencia activa y no pasiva que es capaz de modelar la existencia de quienes entran en ella, entender esto significa que lo que somos o creemos ser se encuentra invariablemente 
en riesgo pues, en un escenario similar es imposible salir de allí siendo el mismo, intacto, sin ningún rasguño.

Quizás esa es la mayor consecuencia de diseñar los espacios educativos exclusivamente desde la razón, a saber, que la mayoría permanece en una sala de clases y luego sale de ella, como si no hubiese acontecido nada, a lo menos nada que haya puesto en peligro la interpretación que se tiene sí mismo y del mundo.

- El mundo es muy extraño a esta hora del dia -dijo-. A eso me refiero. Veas lo que veas, no tengas miedo.

- ¿qué cosa voy a ver?

- No sé todavía - dijo- escudriñando la distancia hacia el sur.

- No parecía preocupado. Yo también fijé la mirada en la misma dirección.

- De pronto se irguió y, con la mano izquierda, señalo una zona oscura en el matorral del desierto.

- Allí esta -dijo-, como si hubiera estado esperando algo que de repente había aparecido.

- ¿qué es?-pregunte.

- Allí está -repitió-, ¡mira!, ¡mira!

(Castaneda, 2000: 96)

Imaginémonos, por un instante, a nosotros mismos en una situación similar, sentados en nuestro escritorio, con la mirada fija, escudriñando la sala de clases, mientras los estudiantes nos observan expectantes.

- Profesor, ¿qué cosa vamos a ver hoy?

- No sé todavía, estoy esperando que algo aparezca-

- ¿Qué es? - preguntan-

- ¡Allí esta!, ¿pueden verlo?

Es muy probable que al comienzo, los estudiantes creyeran que es una broma o que estamos poniéndolos a prueba. 
- ¿Pueden verlo?

Si no nos dice que tenemos que ver, ¿cómo podemos reconocerlo?, necesitamos un mínimo de claridad para identificarlo.

El problema es que "ese mínimo de claridad", históricamente lo ha proporcionado la razón y hemos aprendido a conocer la experiencia primordialmente mediada por sus categorías. La pregunta que debemos hacernos en este punto es, qué tipo de experiencia educativa estamos intencionando, cuando podríamos sentirnos libres de acceder a la totalidad de aquello que aparece en su esencia. Es a esa plenitud y a ese entendimiento al que debemos alinearlos y no exigir a esa totalidad que se ajuste a lo más pequeño, nos referimos a los límites de la razón.

Ahora bien, para acceder a la esencia, más que una planificación o herramienta similar necesitamos educar un temperamento. Esta disposición contempla que el educador este activa y permanentemente alerta en espera de las manifestaciones. Si el educador se entrena en tal disposición de ánimo y percepción sus acciones pueden ser totalmente eficientes, pues lo percibido, en cuanto tal, tiene la fuerza para movilizar la acción.

El educador más que planificar tiene que aprender a "estar presente" y a mirar lo que emerge a cada instante. Pues solo allí están las claves de cómo conducirse. Si un educador deja de estar presente en lo que hace, todo en su mundo circundante deja de comunicar, se vuelve vago y sin propósito. Es fundamental, entonces, aprender a percibir la experiencia como una matriz inteligente que tiene el poder de guiarnos y mostrarnos la acción adecuada. No se trata de despojarnos de la racionalidad, la planificación o la técnica, sino que de intentar otro tipo de mirada.

Este acercamiento a la esencia requiere que dejemos de vigilar -como sostiene Heidegger- técnicamente las cosas y finalmente las dejemos estar allí en su aparecer, permitir que la naturaleza brote a la luz, sin provocarla ni retarlas a que se muestren de un modo calculable y planificado.

A esa Matriz inteligente en la que algo aparece en su esencia la fenomenología también la denomina "campo". 
"En presencia del campo todo se vuelve nítido y prevalece una resonancia profunda con todo lo que emerge. Lo que allí surge es reconocido como si viviera en uno y se vivencia como lo más hermoso". (Bert, 2008: 247)

Cuando estamos en circunstancias donde -un comentario, un relato, una imagen, una mirada, un gesto- es capaz de silenciarnos, de cambiar el flujo de la respiración y resonar en todos los corazones, estamos abrigados por esa matriz inteligente, ese campo que tiene la fuerza de volver memorable lo cotidiano.

Es a esto a lo que nos referimos cuando señalamos que el educador debe ser entrenado en un "temperamento", que responda a una actitud receptiva, abierta y humilde, pues sin ella el educador puede caer en el error de atribuirle la grandeza de ese momento a su propia acción y no a la sintonía con un entendimiento más grande que supera cualquier planificación. El educador tiene que aprender a entregarle a ese campo, su atención total, pues el entendimiento que de allí surge hace comprensible algo esencial, que se reconoce sin esfuerzo y nos libera para actuar de manera diferente y plena.

A modo de cierre, elijo compartir un breve texto de Bert Hellinger, connotado filósofo y fenomenólogo alemán, quién describe este estado de apertura, con la claridad necesaria para imaginar cómo conducirnos en este nuevo camino de entendimiento:

-El primer paso es que uno se expone a esos fenómenos tal como se presentan, sin seleccionar, sin juzgar, a todos tal como son. Y uno asiente a ellos, tal como son. En esa actitud no es necesario cerrarse ante nada. Todo se pone en sintonía con nosotros sin temernos, y nosotros entramos en sintonía con eso, asintiendo a todo tal como es.

-Luego sigue el segundo paso: esperamos hasta que, repentinamente, de esa plenitud a la cual nos exponemos surja algo. Lo que se muestra de esa manera se muestra con fuerza y al mismo tiempo como una demanda. Desde el trasfondo oculto de los fenómenos, de pronto, algo sale a la luz como un rayo y nos muestra qué hay que hacer, y de inmediato. Lo vivimos como proviniendo de afuera, a pesar de que se muestra en el 
interior. Si obedecemos, tiene un efecto tanto en nosotros como en las otras personas expuestas a ello. Porque de esa manera no somos sólo nosotros mismos los que actuamos. Otra cosa actúa a través de nosotros. (Hellinger, 2008: 42)

\section{Referencias bibliográficas}

Castaneda, C. (2000). Viaje a Ixtlán, México, Fondo de cultura Económica

Heidegger, M. (1994), Construir, Habitar y Pensar, Madrid: Editorial Serbal

Heidegger, M. (2000).Carta Sobre el Humanismo, Madrid, Alianza Editorial

Hellinger, B. (2005), La verdad en movimiento, Buenos Aires, Editorial Alma Lepik

Hellinger, B. (2005). La verdad en movimiento, Buenos aires, Editorial Alma Lepik

Hellinger, B. (2008). El Manantial no tiene que preguntar por el camino, Buenos Aires, Editorial Alma lepik

Hellinger, B. (2005), La verdad en movimiento, Buenos Aires, Editorial Alma Lepik

Nietzsche, F. (2002) La Gaya Ciencia, Madrid, Editorial Edaf 